\title{
Diagnostic Assessment of Arterial Lactate Clearance as Predictor of Mortality of Severe Sepsis Patients in Intensive Care Unit
}

\author{
Raka Jati Prasetya ${ }^{1^{*}}$, Achsanuddin Hanafie ${ }^{1}$, Nazaruddin Umar ${ }^{1}$ \\ ${ }^{1}$ Anesthesiology and Intensive Care Department, Faculty of Medicine North Sumatera \\ University, Haji Adam Malik Hospital, Medan, North sumatera, Indonesia
}

\begin{abstract}
ICU mortality rates in severe sepsis remains high; objective instrument to determine disease severity and to predict mortality in ICU patients with severe sepsis is needed. Arterial lactate has become one of the simple and inexpensive marker in the ICU to assess disease severity and prediction of mortality in critically ill patients compared to APACHE II score that requires a lot of expensive laboratory tests and costs. The study was performed at the surgical-medical ICU Haji Adam Malik hospital during May 2013 until August 2013. And the purpose of this study is to know whether arterial lactate clearance can be used a simpler, easier, and cheaper alternative method as a predictor of mortality in ICU patients with severe sepsis.
\end{abstract}

Keywords: Arterial lactate clearance, APACHE II score, ICU mortality.

\section{Introduction}

Sepsis is a life-threatening medical condition characterized by extraordinary infections and the body's inflammatory response to the infection. Sepsis is a common condition in the intensive care unit (ICU) associated with mortality, morbidity, and high costs. ${ }^{1}$ Incidence of sepsis has increased considerably since the late 1970s. In 2000, the number of patients with a sepsis diagnosis was about 660,000 people, an increase of about $9 \%$ per year since 1979. There are 1-2\% of septic patients in hospital care, and more than 50\% of patients are treated in ICU. supportive treatment and antibiotic treatment, decrease mortality about $20 \%$ in hospitals; But death continues to rise, making sepsis the top ten cause of death in the United States. Sepsis is significantly associated with morbidity and economic costs. Because of the still high mortality in ICU caused by sepsis, an objective instrument is needed that can determine the severity of the disease and assessment the predicted mortality of sepsis patients in the ICU. ${ }^{2}$

In general, the score system used in ICU can be classified into a prognostic model score system and an organ dysfunction score. There are 4 generations of prognostic score systems. The first generation is Acute Physiologic and Chronic Health Evaluation I (APACHE I). The second generation consists of APACHE II, Simplified Acute Physiology Score I (SAPS I) and Mortality Probability Model I (MPM I). The third generation is APACHE III, SAPS II, and MPM II. The last generation is APACHE IV, SAPS III, and MPM III ${ }^{(3)}$. APACHE II scores have been reported to predict critical patient mortality, so the scoring system is most used, especially in infectious patients, clinical trials, resource utilization, health care regulation, and on the Surviving Sepsis Campaign ${ }^{4}$. 
Four generations of this prognostic score system are calculated based on clinical and laboratory parameter values. The problem to the application of the scoring system are the many laboratory parameters that may not be available in each intensive care unit (ICU) in Indonesia. In addition, the number of laboratory parameters examined will also increase the financing of care in ICU. Therefore, more simple and inexpensive parameters are needed to replace the scoring system. At present, independent parameters have been studied to predict the mortality of patients treated in ICUI such as $\mathrm{pH}$, base deficit, lactate, anion gap, strong ion difference (SID) and strong ion gap (GIS) ${ }^{5}$.

Lactate levels are among the predictors of prognosis used in ICU. In sepsis patients elevated levels of lactate in the blood are suspected due to interference or tissue perfusion failure. ${ }^{6,7}$ Lactate levels may remain normal although lactate production increases if there is an increase in liver metabolism. Lactate is known to be a non-toxic metabolite substance and is produced by muscles, skin, brain, gastrointestinal tract and red blood cells. In general, normal lactate levels are $<2 \mathrm{mmol} / \mathrm{L}$ with a production of $0.8 \mathrm{mmol} / \mathrm{kg} /$ hour. ${ }^{7}$ Increased lactate levels are the result of production that exceeds the needs and capabilities of metabolism. Several recent studies have shown that the capacity of lactate use in critical pain conditions is not different from normal conditions. This suggests that increased lactate production is a major factor in the occurrence of hyperlactatemia and lactic acidosis. ${ }^{8}$

Hyperlactatemia and lactic acidosis can be used as diagnostic markers and a poor critical condition prognosis. Hyperlactatemia in critical patients is lactate $>18 \mathrm{mg} / \mathrm{dL}(2 \mathrm{mmol} / \mathrm{L})$ and lactic acidosis is metabolic acidosis with lactate levels $>45 \mathrm{mg} / \mathrm{dL}(5 \mathrm{mmol} / \mathrm{L})$ with an arterial $\mathrm{pH}<7.35^{(5,6)}$. Increased lactate formation of critically ill patients occurs not only in hypoxic conditions but may also result from an increased aerobic glycolysis process (cell hypermetabolism) with sufficient oxygen-supply conditions. ${ }^{9}$ In critically ill patients, however, it was found that relative hyperlactataemia was independently associated with increased mortality; Blood lactate concentration> 0.75 mmol.L-1 can be used by clinicians to identify patients at high risk of death. The conclusion may be that the reference range for lactate in critically ill patients needs to be reexamined ${ }^{10}$. Relative hyperlactataemia (lactate value $1.36-2.00 \mathrm{mmol} / \mathrm{L}$ ) in the first 24 hours of ICU treatment was also an independent predictor of mortality in ICU and hospital in critically ill patients ${ }^{11}$.

Acute hypoperfusion can occur due to an imbalance of oxygen demand by oxygen delivery to the tissues. Hipoperfusion is at great risk of causing organ failure. Experimentally and clinically it has been found that if oxygenation to normal tissues is inadequate, blood lactate levels will increase. Blood lactate levels are closely related to outcomes in critical patients. Several studies have shown elevated lactate levels in critical patients despite no signs of shock, presumably due to hypoperfusion ${ }^{12}$. Another study in trauma patients with hypoperfusion showed increased rates of morbidity and early repair of such hypoperfusion may improve the outcome. Other researchers reported that patients treated with cardiac index and oxygen delivery were relatively low with tissue hypoperfusion. Lactate concentration describes the severity of perfusion disorder and is associated with successful treatment.

Many studies targeting early detection and repair of tissue hypoxia, even after normalization of traditional vital signs (heart rate, blood pressure and urine), can also cause significant deaths in severe sepsis and septic shock. ${ }^{14}$ As a measure against tissue hypoxia and risk stratification, lactate measurements have now been incorporated into treatment and treatment protocols. ${ }^{4}$ It has previously been reported that unresolved global tissue hypoxia may be reflected in inadequate lactate clearance during the initial phase of resuscitation leading to organ dysfunction and increased mortality in severe sepsis and septic shock. ${ }^{6}$

In 76 multiple trauma patients, Abramson et al, reported that serum lactate levels were an important prognostic factor ${ }^{15}$. Lactate serial measurements are a reliable indicator for the morbidity and mortality of trauma patients ${ }^{16}$. A study of 87 septic shock patients found that serial serum lactate blood testing by measuring the initial lactate and final lactate (before recovery or death) was a good predictor of multiple organ failure $^{17}$. In the cohort study, Mikkelsen ME et al reported 830 patients with a 28 day mortality assessment and risk factor variables were venous lactate examination $(\mathrm{mmol} / \mathrm{L})$, it was concluded that intermediate values (2-3.9 $\mathrm{mmol} / \mathrm{L})$ and high values $(\geq 4 \mathrm{mmol} / \mathrm{L})$ serum lactate levels were independently associated with independent mortality against organ dysfunction and shock in patients with severe sepsis ${ }^{18}$. And found patients with higher lactate clearance after 6 hours of resuscitation had a better prognosis outcome6. Burn patients have a better life expectancy if lactate levels return to normal within 24 hours ${ }^{19}$. Patients with trauma not die if corrected lactate within 24 hours $^{21}$. In surgical patients treated at ICU, the $10 \%$ mortality ratio at lactate levels returned to normal within 24 hours, $24 \%$ at normal lactate levels $>48$ hours and $67 \%$ if lactate 
levels did not return to normal ${ }^{20}$. Lactate levels that can not return to normal increase the hospital's mortality ratio $42.5 \%$ mortality ratio in patients who achieved normal values between 48-96 hours. Patients with normal lactate levels within 24-48 hours had a mortality ratio of $13.3 \%$ and patients returning to normal values for less than 24 hours the mortality ratio was $3.9 \% .{ }^{21}$ Based on the above studies, this study aims to examine the value of arterial lactate clearance hour-0 to 24-hour as another method of predicting the mortality of severe sepsis patients treated at Haji Adam Malik Hospital ICU.

\section{Experimental}

This study used a diagnostic test design to obtain the sensitivity and specificity of arterial lactate clearance from hour-0 to hour-24 as a predictor of mortality in patients with severe sepsis of ICU in Haji Adam Malik Hospital. The population of this study is all new severe sepsis patients admitted to Intensive Care Unit (ICU) Haji Adam Malik General Hospital Medan from May 2013 until August 2013.

\section{Results and Discussion}

The study was conducted for 4 months from May 2013 to August 2013, against 30 patients who had fulfilled the inclusion and exclusion criteria. The number of research samples were 27 patients (15 male and 12 female). A total of 2 patients, 2 men and 1 women were excluded due to dying less than 24 hours of treatment.

\section{Comparison of living groups and groups died}

Comparisons of the study samples in the life and death groups are shown in Table 1

Table 1. Comparison of living groups and death groups

\begin{tabular}{|l|c|c|c|}
\hline Characteristic & Living Group & Died Group & p \\
\hline Age, mean (SD), Year & $29(11,77)$ & $49,8(16,36)$ & $0,005^{\mathrm{a}}$ \\
\hline Gender, $\mathrm{n}(\%)$ & & & \\
\hline Male & $6(75)$ & $9(47)$ & $0,326^{\mathrm{b}}$ \\
\hline Female & $2(25)$ & $10(53)$ & \\
\hline Diagnostics, $\mathrm{n}(\%)$ & & & \\
\hline Digestive Surgery & $3(37,5)$ & $7(36,8)$ & $0,531^{\mathrm{b}}$ \\
\hline Thoraks Surgery & 0 & $2(10,5)$ & \\
\hline Neuro Surgery & $3(37,5)$ & $1(5)$ & \\
\hline Neurology & 0 & $1(5)$ & \\
\hline Interna & $1(12,5)$ & $6(31)$ & \\
\hline Ortopedi & 0 & $1(5)$ & \\
\hline Obgyn & $1(12,5)$ & $1(5)$ & \\
\hline Artery Lactate at hour-0, mean (SD) & $1,46(0,59)$ & $3,99(4,30)$ & $0,036^{\mathrm{c}}$ \\
\hline Artery Lactate at hour-24th, mean (SD) & $1,31(0,66)$ & $3,14(3,19)$ & $0,162^{\mathrm{c}}$ \\
\hline $\begin{array}{l}\text { Arterial lactate clearance from hour 0 to 24 hours, } \\
\text { mean (SD) }\end{array}$ & $0,86(64,03)$ & $-46,25(190,19)$ & $0,570^{\mathrm{c}}$ \\
\hline APACHE II Score, mean (SD) & $18.43(4,15)$ & $23,25(7.34)$ & $0,115^{\mathrm{a}}$ \\
\hline Long treatment (days), mean (SD) & $19(9,22)$ & $3,85(2,49)$ & $0,0001^{\mathrm{c}}$ \\
\hline
\end{tabular}

${ }^{a}$ T test independent, ${ }^{b}$ Chi square, ${ }^{c}$ Mann Whitney

In this study, arterial lactate was found at hour 0 in the mean life group of 1.46 with standard deviation of $0.59 \mathrm{mmol} / \mathrm{L}$, while the group died averaging $3.99 \mathrm{mmol} / \mathrm{L}$ with a standard deviation of 4.30 mmol / / L. With a value of $\mathrm{p}=0.036$ means there is a significant difference in mean arterial lactate of the clock hours to 0 groups of life and death. The arterial lactate at 24 hours in the live group averaged $1.31 \mathrm{mmol}$ / $\mathrm{L}$ with a standard deviation of $0.66 \mathrm{mmol} / \mathrm{L}$, whereas the group died averaging $3.14 \mathrm{mmol} / \mathrm{L}$ with a standard deviation of $3.19 \mathrm{mmol} / \mathrm{L}$. With a value of $\mathrm{p}=0.162$ means there is no significant difference in mean arterial lactate of 24 hours of life and death group.

This result is the same as Farah A. Husain et al. ${ }^{22}$ Which had an initial arterial lactate value having a significant difference between life and death $(4.2 \mathrm{mmol} / \mathrm{L}, 2.8 \mathrm{mmol} / \mathrm{L}$ and $\mathrm{p}=0.002)$, and so on arterial lactate values after 24 hours had a significant difference between living and Died (5.1 $\mathrm{mmol} / \mathrm{L}, 2.2 \mathrm{mmol} / \mathrm{L}$, and $\mathrm{p}<0.001$ ). 
The arterial lactate discrimination test at the 0th hour, 24th arterial lactate and arterial lactate clearance from the 0th hour to the 24th hour

The ability of a scoring system to distinguish patients who will survive with patients who will die is said to be a test of discrimination. From this discrimination test results will be obtained cut-off point, the sensitivity and specificity of the score system. The results are expressed in receiver operating curve (ROC) curve form. Below this will show the ROC image and the area table below the ROC.

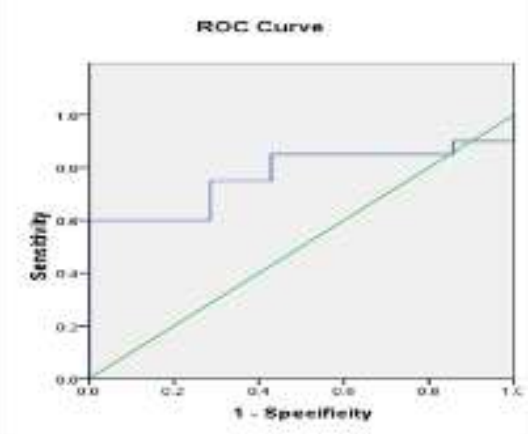

Curve ROC lactate at 0 hours

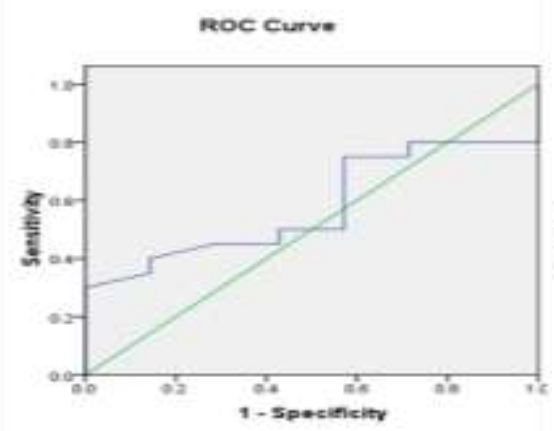

Curve ROC lactate at 24 hours

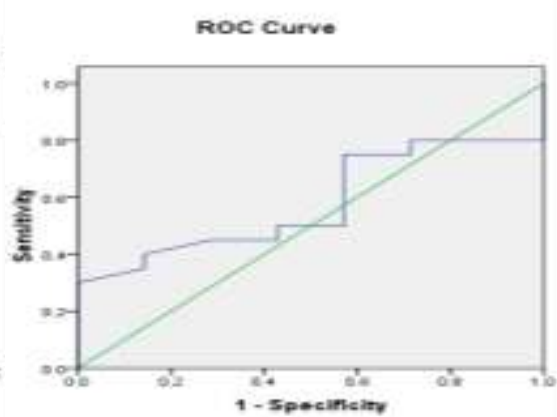

Curve ROC lactate clearence

Table 2 Area area under curve (Area Under Curve) ROC

\begin{tabular}{|l|l|l|l|l|}
\hline & Area & Standard Error & p & IK 95\% \\
\hline Lactate arterial at hour-0 & 0,771 & 0,090 & 0,036 & $0,596-0,947$ \\
\hline Lactate arterial at hour-24th & 0,686 & 0,106 & 0,150 & $0,478-0,894$ \\
\hline Arterial lactate clearence at hour-0 to hour-24th & 0,579 & 0,112 & 0,543 & $0,360-0,797$ \\
\hline
\end{tabular}

In this study, arterial lactate clearance from hour-0 to hour-24th has an area of under curve (AUC) of 0.579 and a cut off point of 27.25 with a sensitivity of 0.500 and a specificity of 0.500 . The area of the AUC of lactate clearance is poorly assessed and low when compared to the lactate AUC area of the hour- 0 and the hour-24th, this reflects the lactate clearance of this can not be used as a predictor of mortality in patients treated at UPI RSHAM.

\section{Conclusion}

This diagnostic test study aims to obtain alternative predictors as another method that can be used in addition to APACHE II score to predict the death of patients with severe sepsis in UPI. Arterial lactate clearance from the 0th hour to the 24th hour can not be used as a predictor of mortality in patients with severe sepsis in UPI, because from the statistical analysis by linear regression it is found that the arterial lactate clearance relationship from the hour to the hour to the 24th hour with APACHE II scores showed a moderate relationship $(\mathrm{r}=0.321)$ and $\mathrm{p}=0.108$ which showed no significant relationship $(\mathrm{p}=0.108)$ between arterial lactate clearance values from the 0th hour to the 24th hour. And the value of the AUC curve of 0.579 is considered bad to be a predictor. The results are different because of the variety of patients treated at UPI RSHAM, lactate examination performed only 2 times when admission and 24 hours later as well as the number of small samples studied in this study.

\section{References}

1. Dean E. Schraufnagel, MD. sepsis. Breathing in America:Diseases, Progress,and Hope. USA: the American Thoracic Society, 2010,. 227.

2. Angus, D. C., Linde-Zwirble, W. T., Lidicker, J., Clermont, G., Carcillo, J., \& Pinsky, M. R. (2001). Epidemiology of severe sepsis in the United States: analysis of incidence, outcome, and associated costs of care. Critical Care Medicine, 29(7), 1303-1310. doi:10.1097/00003246-200107000-00002.

3. Jonathan, M. (2009). Siner, MD. Sepsis: Definitions, Epidemiology, Etiology and Pathogenesis Chest. Chest. s.l. Chest.

4. Dellinger, R. P., Levy, M. M., Carlet, J. M., Bion, J., Parker, M. M., Jaeschke, R., \& Vincent, J.-L., (2008). Surviving Sepsis Campaign: international guidelines for management of severe sepsis and septic shock. Critical Care Medicine, 36, 296-327. doi:10.1097/01.CCM.0000298158.12101.41. 
5. Kaplan, L. J., Kellum, J. A., \& Jhon, A. (2004). Initial pH, base deficit, lactate, anion gap, strong ion difference, strong ion gap predict outcome from major vascular injury. Critical Care Medicine, 32(5), 1120-1124. doi:10.1097/01.CCM.0000125517.28517.74.

6. Nguyen, H. B., Rivers, E. P., Knoblich, B. P., Jacobsen, G., Muzzin, A., Ressler, J. A., \& Tomlanovich, M. C. (2004). Early lactate clearance is associated with improved outcome in severe sepsis and septic shock. Critical Care Medicine, 32(8), 1637-1642. doi:10.1097/01.CCM.0000132904.35713.A7.

7. Backer, D. D. (2003). Lactic acidosis and hyperlactatemia. Intensive Care Medicine, 29, 699-702.

8. BA. Mizock. Lactic acidosis. Elbers PWG, eds. In Kellum JA. Stewart's Textbook of Acid base 2nd ed. USA: s.n., 2009, 376-87.

9. Levy, B. (2006). Lactate and shock state: the metabolic view. Current Opinion in Critical Care, 12(4), 315-321. doi:10.1097/01.ccx.0000235208.77450.15.

10. Nichol, A. D., Egi, M., Pettila, V., Bellomo, R., French, C., Hart, G., \& Cooper, D. J., (2010). Relative hyperlactatemia and hospital mortality in critically ill patients: a retrospective multi-centre study. Critical Care (London, England), 14(1), R25. doi:10.1186/cc8888.

11. Rishu, A. H., Khan, R., Al-Dorzi, H. M., Tamim, H. M., Al-Qahtani, S., Al-Ghamdi, G., \& Arabi, Y. M. (2013). Even Mild Hyperlactatemia is Associated with Increased Mortality in Critically Ill patients. Critical Care (London, England), 17(5), R197. doi:10.1186/cc12891.

12. Meregalli, A., Oliveira, R. P., \& Friedman, G. (2004). Occult hypoperfusion is associated with increased mortality. Critical Care (London, England), 8(2), R60-R65. doi:10.1186/cc2423.

13. Tuchschmidt, J. A., \& Mecher, C. E. (1994). Predictors of outcome from critical illness, shock and cardiopulmonary rescucitation. Critical Care Clinics, 10(1), 179-195. doi:10.1016/S07490704(18)30155-6.

14. Rivers, E., Nguyen, B., Havstad, S., Ressler, J., Muzzin, A., Knoblich, B., . . ., \& Tomlanovich, M. (2001). Early goal-directed therapy in the treatment of severe sepsis and septic shock. The New England Journal of Medicine, 345(19), 1368-1377. doi:10.1056/NEJMoa010307.

15. Abramson, D., Scalea, T. M., Hitchcock, R., Trooskin, S. Z., Henry, S. M., \& Greenspan, J. (1993). Lactate clearance and survival following injury. Trauma, 35(4), 584-589. doi:10.1097/00005373199310000-00014.

16. Manikis, P., Jankowski, S., Zhang, H., Kahn, R. J., \& Vincent, J. L. (1995). Correlation of serial blood lactate levels to organ failure and mortality after trauma. The American Journal of Emergency Medicine, 13(6), 619-622. doi:10.1016/0735-6757(95)90043-8.

17. Bakker, J., Gris, P., Coffernils, M., Kahn, R. J., \& Vincent, J. L. (1996). Serial blood lactate levels can predict the development of multiple organ failure following septic shock. American Journal of Surgery, 171(2), 221-226. doi:10.1016/S0002-9610(97)89552-9.

18. Mikkelsen, M. E., Miltiades, A. N., Gaieski, D. F., Goyal, M., Fuchs, B. D., Shah, C. V., . ., \& Christie, J. D. (2009). Serum lactate is associated with mortality in severe sepsis independent of organ failure and shock. Critical Care Medicine, 37(5), 1670-1677. doi:10.1097/CCM.0b013e31819fcf68.

19. Kamolz, L. P., Andel, H., Schramm, W., Meissl, G., Herndon, D. N., \& Frey, M. (2005). Lactate: early predictor of morbidity and mortality in patients with severe burns. Burns, 31(8), 986-990. doi:10.1016/j.burns.2005.06.019.

20. McNelis, J., Marini, C. P., Jurkiewicz, A., Szomstein, S., Simms, H. H., Ritter, G., \& Nathan, I. M. (2001). Prolonged lactate clearance is associated with increased mortalility in the sugical ICU. American Journal of Surgery, 182, 481-485. doi:10.1016/S0002-9610(01)00755-3.

21. Blow, O., Magliore, L., Claridge, J. A., Butler, K., \& Young, J. S. (1999). The golden hour and the silver day: detection and correction of occult hypoperfusion within 24 hours improves outcome from major trauma. The Journal of Trauma, 47(5), 964-969. doi:10.1097/00005373-199911000-00028.

22. Husain, F. A., Martin, M. J., Mullenix, P. S., Steele, S. R., \& Elliott, D. C. (2003). Serum lactate and base deficit as predictors of mortality and morbidity. American Journal of Surgery, 185(5), 485-491. doi:10.1016/S0002-9610(03)00044-8. 